ARTIG0

Recebido em: 22/01/2014

Aceito em: $27 / 07 / 2014$

\title{
Análise dinâmica de redes sociais de coparticipação em bancas de defesa de teses e dissertações: um estudo de caso a partir de múltiplos indicadores na área da Ciências da Comunicação \\ Dynamic social network analysis of co-participation in defense of theses and dissertations: a case study from multiple indicators in Communication Sciences
}

Dalton Lopes MARTINS ${ }^{1}$

\section{RESUMO}

A análise dinâmica de redes sociais é uma área ainda pouco explorada no campo da Análise de Redes Sociais, sobretudo no Brasil, trazendo a perspectiva de ampliar os estudos estruturais de rede para incorporar aspectos evolutivos e temporais de como a rede se desenvolvem. 0 artigo trabalha com um estudo de caso na área da Ciências da Comunicação através dos dados coletados do portal Univerciencia.org, aplicando um conjunto de 10 indicadores que serão analisados ao longo de um período de 26 anos num conjunto de 1953 documentos. 0 artigo mostra como a rede se desenvolve de forma fragmentada e dependente da ação de grupos locais ainda desarticulados entre si.

PALAVRAS-CHAVE: Análise de redes sociais. Cientometria. Colaboração.

\begin{abstract}
The dynamic analysis of social networks is a fairly unexplored area in the field of Social Network Analysis, especially in Brazil, bringing the prospect of expanding the network structural studies to incorporate temporal evolution of how the network evolves. The article works with a case study in the area of Communication Sciences of the data collected through the portal Univerciencia.org, applying a set of 09 indicators to be analyzed over a period of 26 years in a set of 1953 documents. The article shows how the network evolves in a fragmented and dependent way on the action of local groups.
\end{abstract}

KEYWORDS: Social network analysis. Scientometrics. Collaboration.

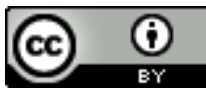

sta obra está licenciada sob uma Licença Creative Commons.

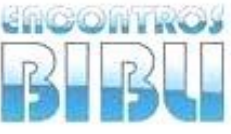

v. 19, n. $40,2014$. p. $99-116$

ISSN 1518-2924

\footnotetext{
${ }^{1}$ Universidade Federal de Goiás - dmartins@gmail.com
} 


\section{INTRODUÇão}

O surgimento do estudo formal da análise de redes sociais esteve ligado com a teoria social e com formalismos matemáticos que embasavam a pesquisa da relação entre objetos de um determinado conjunto. Esse formalismo inicial esteve influenciado conceitualmente por uma visão estruturalista da sociedade (WAASERMAN, FAUST, 1994, p. 5), que buscava explicar a sociedade não apenas a partir de seus elementos, mas sim a partir da estrutura formada pelas relações entre esses elementos.

0 estruturalismo se manteve como o enfoque principal da análise de redes até final dos 90 e começo dos anos 2000, quando a chegada de novos métodos oriundos da dinâmica e complexidade de sistemas começaram a ser utilizados, trazendo novos resultados e alargando os horizontes da pesquisa em análise de redes. Vale a pena ressaltar que a chegada de novos métodos de análise se deve, principalmente, ao fato de que grandes bases de dados relacionais estavam disponíveis e que os métodos tradicionais de análise de redes não davam conta de tratar problemas complexos dessa ordem. As primeiras bases de dados utilizadas para o estudo de aspectos dinâmicos das redes foram as tabelas de roteamento entre servidores na Internet e os padrões de links entre páginas Web (BARABASI, 2003). Sem dúvida, nunca antes na história da ciência, bancos de dados relacionais contendo conexões da ordem de milhões estiveram disponíveis, como estiveram a partir do final dos anos 90. Apesar disso, a visão estruturalista não deixou de ter importância e continua sendo uma linha utilizada pelos pesquisadores, dependendo do contexto do problema que desejam estudar.

A questão chave da pesquisa estruturalista é que ela enfocava as redes como sendo formadas de pura estrutura com propriedades que não se modificam ao longo do tempo (WATTS, 2003). 
As questões da pesquisa estruturalista tinham por objetivo investigar qual era a estrutura formada por uma determinada rede e classificar seus atores conforme as diferentes posições que poderiam ocupar dentro dessa estrutura, utilizando para isso diversos modelos matemáticos. Essa classificação de posições permitiria identificar diferentes níveis de influência dos atores na estrutura, basicamente determinando atores centrais, intermediários, periféricos, laços fortes e fracos entre eles, além da possibilidade de identificação de sub-grupos constituindo zonas de articulação dentro da rede.

A identificação de sub-grupos se tornou um tema de grande interesse pois dispõe de métodos para investigar grupos dentro de uma rede que apresentam um padrão de interatividade entre si que difere de como se relacionam com o restante da rede. A crença na investigação dos sub-grupos, dentro da visão estruturalista, é de que interação social é a base para solidariedade, compartilhamento de normas e comportamento coletivo. Esperase encontrar maiores semelhanças entre pessoas que interagem mais entre si do que com outras dentro do contexto de uma rede (NOOR, MRVAR, BATAGELJ, 2005, p. 61). Outra questão de interesse relacionada a identificação de subgrupos, é a capacidade de identificação de atores que servem como pontes entre sub-grupos. São os chamados conectores. Acredita-se que eles têm alta capacidade de influência, pois podem servir de elementos que transmitem informação de um grupo para o outro dentro de uma rede.

A visão estruturalista da análise de redes sociais teve grande repercussão na ciência, influenciando a pesquisa em diversas áreas (WAASERMAN, FAUST, 1994, p. 5). No entanto, um problema fundamental ainda não poderia ser tratado apenas dessa forma: faltava considerar o aspecto dinâmico das redes. Ao invés de considerar as redes como entidades que se desenvolvem sob a influência de forças sociais, os analistas estruturalistas tinham a tendência de tratar essas forças como fixas no padrão estrutural apresentado por uma rede. 
Deste ponto de vista, a estrutura da rede revelada por seus indicadores estruturais fornecia toda a informação social necessária para analisar o comportamento dos atores e suas respectivas relações de força em rede (WATTS, 2003, p. 50).

A dinâmica de redes considera que os atores são entidades que evoluem ao longo do tempo. Suas propriedades e atributos mudam, assim como a maneira que irão interagir, levando a uma reconfiguração global da estrutura da rede quando analisada no tempo. É essa perspectiva que permite entendermos as redes sociais como sistemas dinâmicos, onde podemos ampliar o escopo de análise, não considerando apenas suas propriedades topológicas/estruturais, mas também suas propriedades dinâmicas. A dinâmica da rede surge como possibilidade de pesquisa quando observamos o processo que ocorre quando as conexões e atores surgem ou desaparecem da rede, indicando a maneira que a estrutura será alterada ao longo do tempo (NEWMAN, BARABASI, WATTS, 2006, p. 7).

A compreensão básica que emerge é que a estrutura afeta as conexões que um ator pode fazer e as conexões que um ator pode fazer afetam a estrutura da rede. Como se pode notar, não é um processo linear, com uma relação direta de causa e efeito. Denota um problema complexo, onde parte e todo se afetam mutuamente, gerando ciclos de realimentação que podem aumentar ou subtrair tendências que não poderiam ser previstas inicialmente. É essa a característica emergente das redes sociais, evidenciando a relação e interdependência da parte com o todo e do todo com a parte.

A visão dinâmica das redes tem influenciado importantes temas de pesquisa, onde tem sido aplicada nos últimos anos (WATTS, 2004):

- dinâmica humana;

- contágio social e de doenças;

- modelos de dinâmicas de sistemas;

- algoritmos de buscas de informações;

- sistemas robustos. 
O objetivo maior da nova ciência das redes é entender como a estrutura de uma rede opera em nível global dependente de processos dinâmicos que operam em nível local. É uma visão que busca integrar macro e micro análise, considerando e integrando padrões dinâmicos e estruturais, podendo atuar em três níveis distintos de análise: macroestrutura, mapeando o contexto e sua evolução no qual uma rede está inserida, mesoestrutura, mapeando como a estrutura de uma rede é formada e como evolui ao longo do tempo, microestrutura, mapeando as especificidades estruturais e dinâmicas dos atores envolvidos diretamente na rede (BRITTO, 2008, p. 109) (RAIDER, KRACKHARDT, 2001). Questões relacionadas a como um padrão emergente ocorre, com que frequência ocorre e com que consequências, são pontos que podem ser resolvidos pela junção da abordagem estrutural e dinâmica, bem como da relação entre as duas (NEWMAN, BARABASI, WATTS, 2006, p. 7).

De modo a avaliar como uma rede evolui ao longo do tempo e como podemos nos apropriar desse modo dinâmico de leitura para questões de interesse na área da Análise de Redes Sociais, vamos neste artigo analisar a dinâmica de uma rede de co-participação de pesquisadores em bancas de defesas de teses e dissertações na área da Ciências da Comunicação. 0 artigo está organizado em 6 seções, sendo elas a seção 2 onde apresentamos os indicadores e seu significados para este estudo, a seção 3 onde vemos o resumo do caso, a seção 4 onde temos a metodologia utilizada, a seção 5 de resultados de nossas análises, a seção 6 de conclusão.

\section{INDICADORES DE ANÁLISE DE REDES SOCIAIS}

Os indicadores utilizados são os sugeridos por Newman (2001) em um artigo onde estuda de forma estrutural um conjunto de redes sociais de coautoria em diferentes áreas do conhecimento, no caso, medicina, ciência da computação e física. Consideramos que analisar esse conjunto de indicadores em sua forma dinâmica pode ser uma contribuição interessante para a pesquisa em análise de redes sociais, além de permitir possíveis comparações futuras entre resultados de outras de outras áreas do conhecimento. 
Apresentamos de modo resumido os principais indicadores utilizados (a execeção da análise de componentes, que não fez parte deste presente artigo) e seus significados na tabela 1 , a seguir.

\begin{tabular}{|c|c|}
\hline Indicadores & Significado \\
\hline Nós & Número de pessoas que participaram da rede. \\
\hline Links & Número de links estabelecidos entre as pessoas. \\
\hline Densidade média & $\begin{array}{l}\text { Número relativo de conexões estabelecidas em } \\
\text { relação ao máximo possíve }\end{array}$ \\
\hline Componentes & $\begin{array}{l}\text { Número de pedaços da rede que estão isolados } \\
\text { de outras partes }\end{array}$ \\
\hline$\%$ dos nós no maior componente & $\begin{array}{l}\text { Porcentagem de todos os nós da rede que faz } \\
\text { parte do maior componente }\end{array}$ \\
\hline Tamanho do maior componente & $\begin{array}{l}\text { Quantidade de nós que fazem parte do maior } \\
\text { componente }\end{array}$ \\
\hline Tamanho do segundo maior componente & $\begin{array}{l}\text { Quantidade de nós que faz parte do segundo } \\
\text { maior componente. }\end{array}$ \\
\hline Grau de centralização da rede & $\begin{array}{l}\text { Grau de centralização ponderado por todos os } \\
\text { nós da rede, quanto maior o grau mais } \\
\text { centralizada em torno de poucos nós é uma rede, } \\
\text { quanto menor, mais distribuída é uma rede. }\end{array}$ \\
\hline Coeficiente de Clusterização & $\begin{array}{l}\text { Coeficiente que determina a transitividade de } \\
\text { relações relativas entre os nós da rede. }\end{array}$ \\
\hline Coeficiente de Potência & $\begin{array}{l}\text { Coeficiente que determina como uma rede se } \\
\text { comporta em relação aos seus grupos e nós mais } \\
\text { centrais. }\end{array}$ \\
\hline
\end{tabular}

\section{RESUMO DO CASO}

0 portal Univerciencia.org é uma biblioteca digital federada com foco específico na área das Ciências da Comunicação. Possui 49 fontes de informação de revistas científicas e 12 bibliotecas digitais de teses e dissertações de programas de pós-graduação específicos da área. Um detalhamento de quais revistas científicas e a contribuição de cada uma delas em termos de quantidade de artigos, origem e dinâmica de evolução ao longo dos anos do estudo pode ser encontrado em Martins e Ferreira (2012). No período de nossa extração de dados, realizada em dezembro de 2011, o banco de dados registrava 11.825 documentos disponíveis para consulta, sendo distribuídos entre $9.864(83,4 \%)$ artigos de revistas científicas e 1.961 (16,6\%) teses e dissertações.

Em termos de abrangência de pessoas que publicaram algum conteúdo que tenha sido registrado pela biblioteca, temos, após um processo de tratamento e normalização dos nomes, 9.587 nomes distintos de pesquisadores na base de revistas científicas e 2.465 nomes distintos de participantes registrados nas bibliotecas digitais de teses e dissertações. Além disso, os dados 
mais antigos de bancas de defesa são de 26 anos atrás e de 15 anos no caso das revistas científicas. Pelos números expostos acima, a Univerciencia.org é considerado o maior repositório brasileiro na área de Ciência da Comunicação.

Utilizaremos para a realização deste estudo de caso apenas os dados relativos aos documentos provenientes das bibliotecas digitais de teses e dissertações, dado que nosso foco são as relações de coparticipação em bancas de defesas, logo trabalhamos com um universo de 1961 documentos e 2.465 nomes de pesquisadores que participaram dessa produção científica ao longo de 16 anos de publicação.

\section{METODOLOGIA}

A pesquisa realizada é de cunho quantitativo tendo sido utilizado o banco de dados da biblioteca digital federada Univerciencia.org como amostra de dados para as análises realizadas, sendo estas organizadas em torno de um conjunto de indicadores de análise de redes sociais apresentados anteriormente com o objetivo de permitir diversos olhares possíveis para como se dá a dinâmica de evolução da rede de coparticipação em bancas entre esses pesquisadores analisados, permitindo caracterizar diversos eventos de relevância que contribuem para o entendimento dessa dinâmica.

Os dados foram coletados diretamente do banco de dados do site Univerciencia.org. Coletamos apenas os metadados das bibliotecas digitais. Os metadados são padronizados em suas fontes de origem no padrão Dublin Core Simplicado, o que nos permitiu analisarmos apenas os campos dc:author e dc:contributor. Esses campos indicavam, quando disponíveis, os nomes de todos os participantes de uma banca, incluindo o autor do trabalho a ser defendido. Os nomes identificados foram normalizados.

De modo a analisarmos a dinâmica de evolução dessa rede, os dados foram trabalhados de modo a construirmos uma matriz de análise, cruzando todos os pesquisadores que se relacionaram entre si, organizados pelos atributos biblioteca de origem e ano de relacionamento. Os dados foram então analisados ano a ano e, eventualmente quando achamos necessário para 
entender melhor alguns efeitos dinâmicos que serão apresentados a seguir, de forma acumulada, somando-se todos as relações durante um período de tempo e as considerando válidas para uma análise específica. A análise ano a ano permitia considerar como uma rede válida para um determinado ano apenas as relações entre autores que aconteceu naquela ano específico, permitindo entendermos como a rede ia se organizando e desenvolvendo de um ano para o outro.

Os dados foram tratados pelo software Pajek2.

\section{RESULTADOS DA ANÁLISE DE REDES SOCIAIS}

Os resultados da análise serão apresentados separadamente por indicador utilizado, sendo apresentada ao final uma síntese dos mesmos visando facilitar um entendimento geral dos resultados bem como de suas possíveis conclusões.

\subsection{Nós e links}

Apresentamos em conjunto a evolução dos nós e links estabelecidos na rede de pessoas que colaboram em torno das defesas de teses e dissertações. Vejamos na figura 1 seus resultados.

Figura 1. Nós e links - modo ano-a-ano e acumulado.
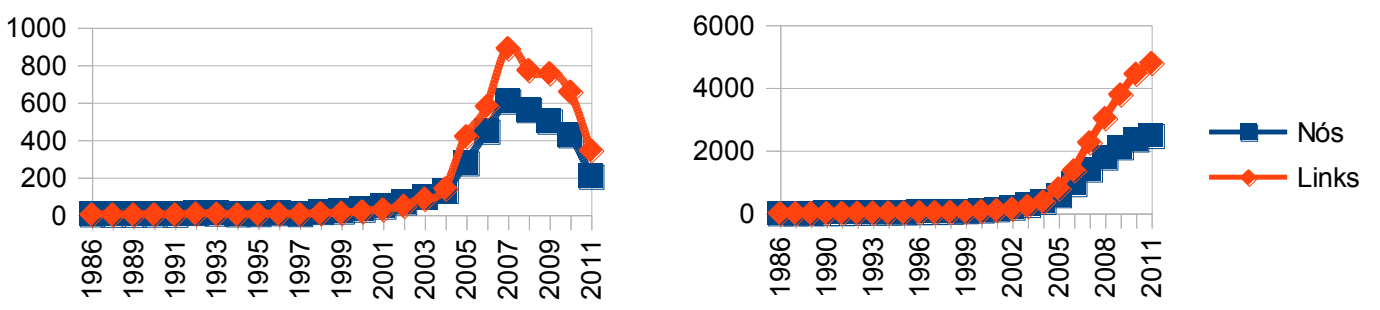

Fonte: Dados da pesquisa.

Percebemos aqui uma relação direta entre o número de documentos sendo produzidos e o número de nós e links sendo estabelecidos na rede. É importante ressaltarmos aqui que o número de nós segue a mesma tendência do número de links, ou seja, mais conexões ocorrendo nessa rede significa mais pessoas atuando nas relações sociais e não um aumento na intensidade das conexões entre os nós ali já existentes. 
Analisando o gráfico da figura 1, notamos que do ano de 2004 para 2005 ocorreu um aumento de aproximadamente $280 \%$ no número de links. Analisando os dados de entrada, percebemos que no ano de 2005 há a entrada de duas bibliotecas digitais em nossa base que disponibilizam informações sobre os membros participantes das bancas de defesa, sendo elas a UFMG e PUC-Rio. Dado que em períodos anteriores tínhamos apenas duas bibliotecas digitais em nossa base disponibilizando esse tipo de informação, é de se esperar que tenhamos um aumento significativo a partir desse período no número de links sendo estabelecidos. Para ilustrar como ocorre essa transição em termos estruturais, mostramos na figura 2 os sociogramas da rede de relações em 2004 e 2005.

Figura 2. Rede de relações em bancas de defesas no ano de 2004 e 2005 - modo ano-a-ano e acumulado.

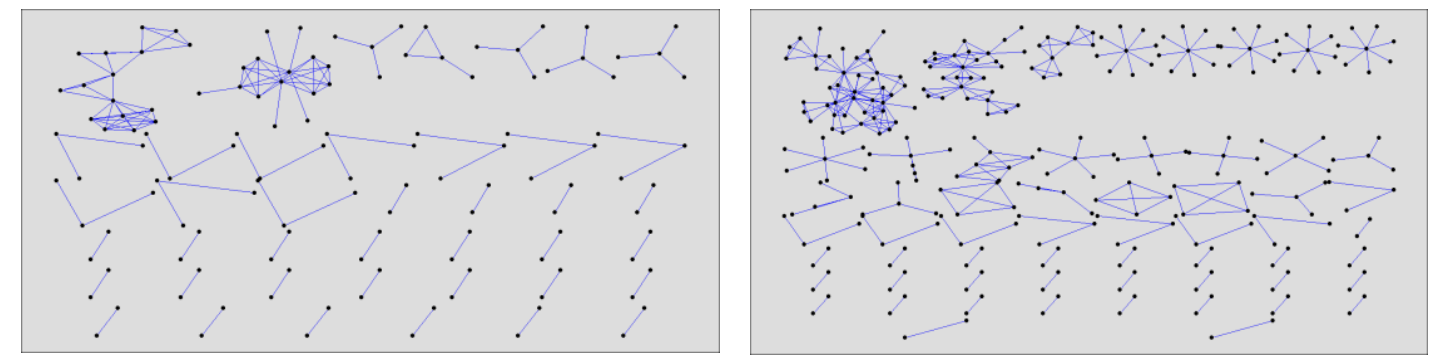

Fonte: Dados da pesquisa.

Analisando as duas imagens, percebemos que os componentes mais simples, ou seja, aqueles formados por duas ou três relações representam metadados gerados por bibliotecas que apenas mostram as relações criadas entre orientadores e orientandos. Os componentes em formato estrela, presentes mais intensamente no modo acumulado (parte direita da figura), também representam esse tipo de relação, porém indicam orientadores que tiveram mais de 2 orientandos que defenderam suas teses ou dissertações no mesmo ano. Já a principal diferença na estrutura das duas redes, o que é sinalizado pelo número de links que cresce do modo como relatamos acima, é termos componentes maiores e com maior número de articulações no ano de 2005 em relação ao ano de 2004. Isso é produto direto não só do fato de termos mais documentos sendo produzidos em 2005, mas pelo fato de termos mais bibliotecas digitais que apresentam em seus metadados as relações de todos os pesquisadores que participaram de uma banca de defesa e não apenas a relação entre orientadores e orientados. Sem dúvida, como esses dados demonstram, termos essas informações completas nos permitem 
avaliar com maior precisão a dinâmica e estrutura de evolução de uma rede social de participantes.

\subsection{Densidade média e grau de centralização}

Apresentamos as curvas de densidade média e grau de centralização da rede de participantes das bancas na figura 3 .

\section{Figura 3. Densidade média e grau de centralização - modo ano-a-ano e} acumulado.
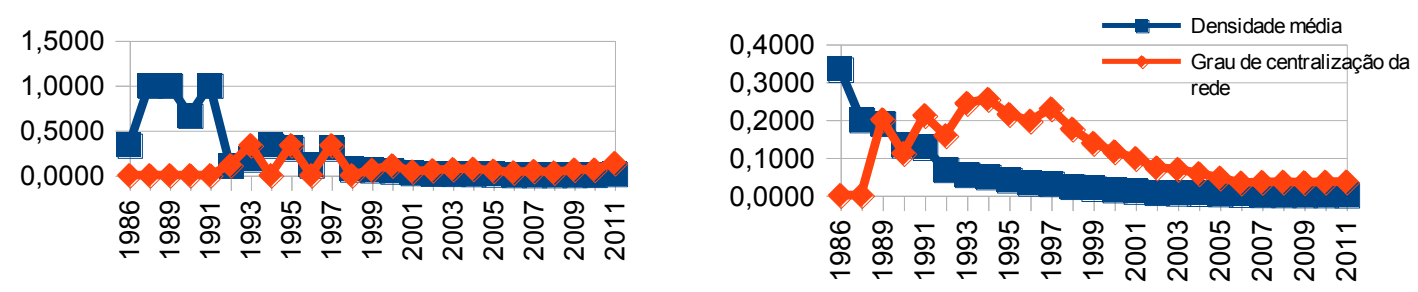

Fonte: Dados da pesquisa.

Observando a figura 3, notamos que a densidade média atinge valores relativos bastante altos no começo do período de análise de nossa base de dados, decaindo abruptamente no ano de 1992, tendo pequena recuperação nos próximos anos, porém seguindo a partir de 1998 em valores próximo a 0. Quando observamos o modo acumulado, a densidade média na rede acumulada decai gradativamente até atingir patamares próximo a zero a partir do ano de 2001, seguindo essa mesma tendência até o final do período de análise. Conforme o aumento no número de nós em uma rede, é natural esperarmos que a densidade média da rede tenda a se reduzir, dado que os nós entram na rede com algumas poucas conexões, sobretudo quando consideramos que estamos aqui retratando relações estabelecidas na participação de bancas de defesas de teses e dissertações. Para ilustrarmos como isso ocorre em termos estruturais, tomemos como exemplo os anos de 1991 e 1992, onde apresentamos a seguir as imagens de seus sociogramas. 
Figura 4. Rede de relações em bancas de defesas no ano de 1991 e 1992- modo ano-a-ano.
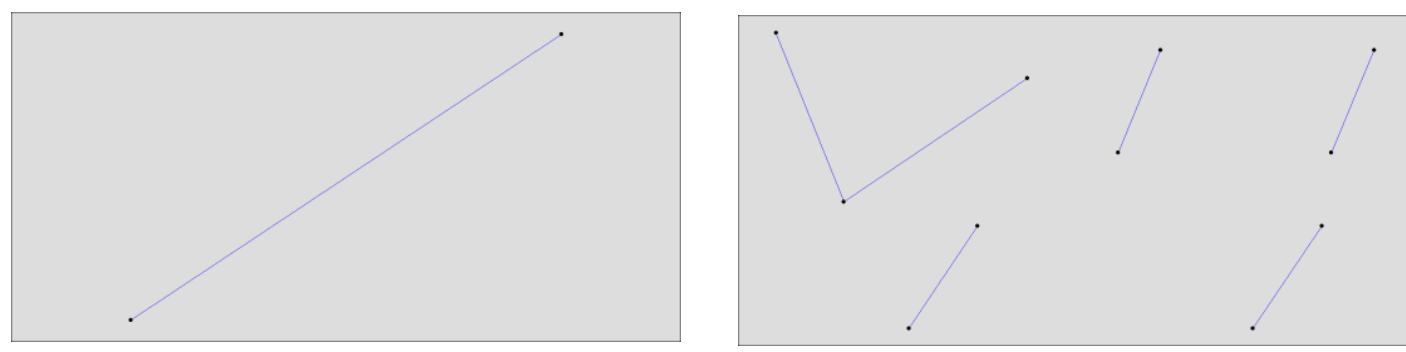

Fonte: Dados da pesquisa.

Observando a rede na figura 4, no ano de 1991, notamos que todas as relações que poderiam ser estabelecidas dado que temos apenas um único componente na rede estão estabelecidas, ou seja, não existem conexões em potencial a serem realizadas na rede. Isso faz com que a densidade média da rede seja considerada $100 \%$, o que percebemos no gráfico da figura 3. Já no ano de 1992, temos uma pequena mudança estrutural na forma da rede, onde notamos um orientador que se relaciona com dois orientandos, mas que não possuem relações diretas entre si. Nesse caso, a densidade da rede cai, dado que há relações em potencial que poderiam ter sido estabelecidas e não foram.

Quando observamos o grau de centralização na figura 3, notamos que ele começa com valores zero nos primeiros anos da rede, tendo picos nos anos de 1993, 1995 e 1997 e novamente seguindo em valores próximos a zero desde então até o fim do período de análise na rede modo ano-a-ano. Já na rede em modo acumulado, notamos que o grau tem um pico em 1987, aumentando e decaindo até atingir um novo pico em 1994 e decaindo gradativamente desde então até o fim do período de análise. Esses dados nos mostram um fenômeno interessante de analisar em termos de como evoluiu o padrão estrutural dessa rede. 0 que nossos gráficos nos levam a concluir é que a rede produz formas que concentram centralidade até o ano de 1997, passando a partir de então essas formas terem menos influência no modo de organização.

Na rede em modo acumulado, essas formas podem ser traduzidas pelo fato de um orientador ir acumulando orientações ao longo de seu tempo de atuação profissional, fazendo com sua rede de interação tome a forma de uma espécie de estrela, com ele no centro. Como não temos a presença de dados de participação dos membros de bancas até o ano de 2001, a partir de quando há documentos na biblioteca digital UFBA disponibilizando essa informação em seus metadados, entendemos esse fenômeno de centralização atrelado diretamente ao acúmulo de orientações realizadas por determinados orientadores em nossa rede. Essa influência é menos perceptível na 
rede em modo ano-a-ano, dado que orientações realizadas em um ano $\mathbf{n}$ não são reconhecidas como relações na rede no ano $\mathbf{n + 1}$, fenômeno que acaba sendo responsável pelos picos e vales que observamos dos anos de 1993 até 1997 na curva do grau de centralização, na figura 3. Para ilustrar esse fato, apresentamos a seguir os sociogramas de dois anos desse período, 1996 e 1997.

Figuras 5. Rede de relações em bancas de defesas no ano de 1996 e 1997 - modo ano-a-ano.
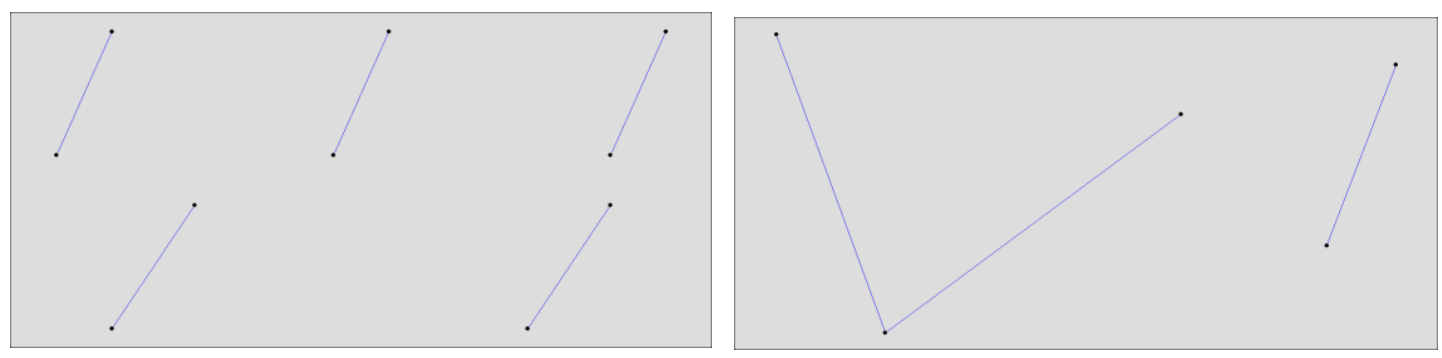

Fonte: Dados da pesquisa.

No ano de 1996 quando o grau de centralização é zero, a figura não demonstra nenhuma forma de concentração de centralidade na rede, dado que todos os nós ali presentes estão de forma homogênea, mostrando relações diretas entre orientadores e orientandos. Já no ano de 1997 temos uma pequena mudança estrutural que leva a uma concentração de centralidade na rede, onde notamos um orientador que se relaciona com dois orientandos, sendo que esses não se relacionam diretamente entre si. Logo, são mudanças desse modo que levam aos efeitos que notamos nas curvas apresentadas.

De qualquer modo, vale ressaltar que esses eventos são bastante sensíveis em uma rede com poucos nós e links como é nossa rede, sobretudo em seus primeiros anos de existência. Ao longo do tempo, tanto a densidade média quanto o grau de centralização tendem a se estabilizar, dado que não ocorre nenhum evento que impacta tão sensivelmente a estrutura da rede quando temos mais nós e links do que nos períodos iniciais.

\subsection{Coeficiente de clusterização}

O coeficiente de clusterização é um indicador que avalia a probabilidade média de que dois nós que são vizinhos de um mesmo nó se tornem conectados em algum momento. Apresentamos na figura 6 a dinâmica do coeficiente de clusterização para nossa rede de coautoria em revistas científicas. 
Figura 6. Coeficiente de clusterização: modo ano-a-ano e acumulado.
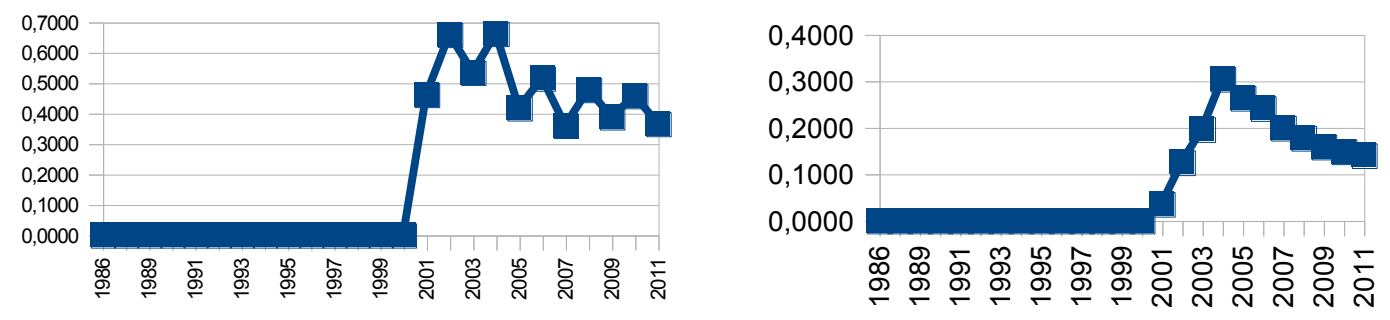

Fonte: Dados da pesquisa.

Observando os gráficos, notamos que o coeficiente de clusterização possui valor zero até o ano de 2001. Essa informação nos mostra que não houve transitividade de relações nessa rede até então, onde temos que dois nós que tenham se conectado a um terceiro não se conectaram entre si até então. Esse resultado é de se esperar, dado que até o ano de 2001 não temos em nossa base nenhuma biblioteca digital que apresente dados dos membros que participaram em suas bancas de defesas, ou seja, o que estamos aqui observando são as relações diretas entre orientadores e orientandos não havendo registros de conexões entre orientadores ou mesmo entre orientandos em nossa base. Já a partir de 2001 essa dinâmica muda, com a entrada dos dados da biblioteca digital da UFBA, já mostrando as primeiras relações entre membros de bancas. Para ilustrar como esse fato se dá em termos estruturais de nossa rede em análise, mostramos na figura 7 os sociogramas da rede em modo ano-a-ano para os anos de 2000 e 2001.

Figura 7. Rede de relações em bancas de defesas no ano de 2000 e 2001 - modo ano-a-ano.

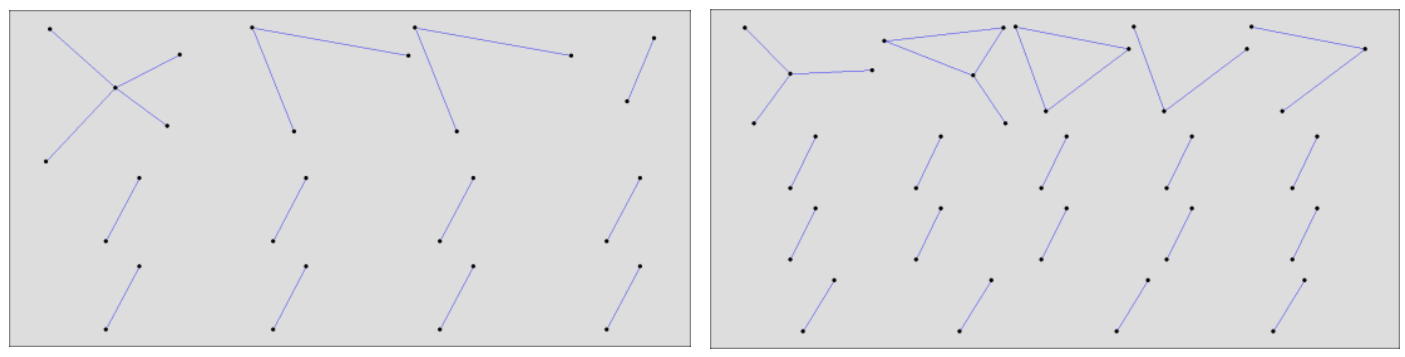

Fonte: Dados da pesquisa.

Observando a rede no ano de 2000, não identificamos nenhuma transitividade de relação entre os pesquisadores, apenas relações diretas entre orientadores e orientandos. Já em 2001 notamos os primeiros triângulos a se formarem na rede, mostrando ao menos três pesquisadores que se relacionaram diretamente entre si, evidenciando outra dinâmica de relação que passa a estar presente em nossa rede. É, 
portanto, essa dinâmica que vai elevando gradativamente o coeficiente de clusterização até o ano de 2004 para a rede vista pelos modos ano-a-ano e acumulado. Isso indica que mais triângulos vão se formando, ampliando a taxa de transitividade entre os pesquisadores.

No entanto, a partir do ano de 2005 esse coeficiente passa a cair gradativamente até o final de nosso período. Esse evento condiz exatamente com o mesmo momento em nossa rede que os componentes estão começando a se juntar e gerando um componente principal de maior relevância na dinâmica organizacional dos nós. Ao formarem um componente principal mais significativo em termos de nós participantes, nossos dados aqui relatados indicam que ao mesmo tempo a rede diminui a sua taxa de transitividade, deixando de atuar em pequenos componentes onde os triângulos têm menos nós em potencial para se formarem passando a ser composta por maiores componentes com mais nós em potencial para transitarem entre si.

Esse crescimento da rede diminui sua taxa de transitividade, chegando a $15 \%$ em 2011 para a rede em modo acumulado, indicando que é essa a probabilidade dos nós transitarem entre si ao final de nosso período, valor que ainda se encontra dentro da faixa documentada em nossa revisão bibliográfica para outras redes sociais. Já para a rede em modo ano-a-ano, o valor final do período é em torno de $40 \%$, apresentando um valor relativo maior de transitividade entre os participantes de nossa rede que participam em conjunto anualmente. Isso nos leva a inferir que se considerarmos apenas os participantes ativos em um determinado ano, eles possuem uma probabilidade maior de transitarem entre si do que quando consideramos a rede em modo acumulado. Fato que era de se esperar, dado que pessoas somente podem se articular entre si quando ativas e produtivas numa determinada área do conhecimento. 


\subsection{Coeficiente de potência}

Figura 8. Coeficiente de potência - modo acumulado.

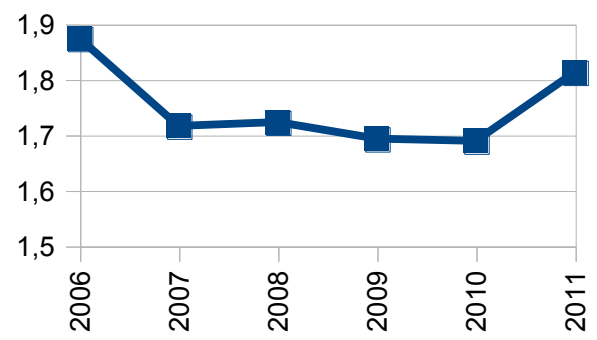

Fonte: Dados da pesquisa.

A curva do coeficiente de potência para a rede em modo acumulado é apresentada na figura 8. Vale dizer que consideramos em nossa análise apenas a rede em modo acumulado, de maneira a termos a maior quantidade possível de nós presentes na rede para melhorar a precisão do cálculo do coeficiente de potência.

O coeficiente oscila do valor 1,9 caindo para 1,7 de 2007 até 2010 e subindo novamente para um 1,8 em 2011. Observamos que os valores são abaixo de 2,0 durante todo o período, o que nos leva a concluirmos que a rede é dominada por poucos indivíduos que possuem um número muito grande de colaboradores, normalmente, os orientadores de muitos alunos e participantes de requisitados de bancas registramos nos dados disponíveis pelas bibliotecas digitais em análise.

Vale mencionar aqui para reforçar esse argumento o fato de termos um maior componente expressivo nesta rede, além do crescimento contínuo do maior grau de conectividade, demonstrando que há nós em nossa rede que terminam por obter altos níveis de centralidade em relação aos demais.

\section{CONCLUSÃO}

A análise de rede sociais é um campo ainda em desenvolvimento e amadurecimento no Brasil com poucos trabalhos acadêmicos, teses e dissertações defendidas utilizando seus princípios de análise, sobretudo no que consiste a análise dinâmica de redes. A área apresenta ainda suas primeiras experiências e resultados de larga escala carecendo de estudos que permitam experimentarmos diferentes composições de indicadores, modos de observação estruturais, mas também maior exploração da análise dinâmica de redes, o que foi um de nossos focos de experiência deste artigo. Acreditamos que nosso 
estudo, pela abrangência e escala temporal, permitiu experimentarmos de modo significativo a análise dinâmica de redes, criando campo de experiência para o aprofundamento de técnicas e possibilidades de pesquisa em estudos futuros, sobretudo no que concerne a sua aplicação na área da pesquisa relacionada a coautoria.

Em relação ao conjunto de indicadores e a nossa matriz de análise, vale dizer que ela se mostrou bastante adequada para o tipo de análise a que nos propusemos. Através dessa composição de indicadores utilizados, pudemos identificar diferentes movimentos, padrões estruturais e dinâmicos em nossas redes analisadas, facilitando com que pudéssemos integrar nossa análise percebendo efeitos distintos e compostos. Os indicadores facilitaram encontrarmos os principais eventos que influenciaram a dinâmica de cada uma das redes, inclusive nos permitindo checarmos os dados encontrados e identificar importantes resultados registrados nos metadados.

Em relação a escolha de realizarmos as análises em dois modos temporais, chamados nesta tese de acumulado e ano-a-ano, vale dizer que eles se mostraram de fundamental importância por mostrarem diferentes tendências quando nos interessa o efeito da evolução dinâmica da rede. Pudemos ali identificar com facilidade eventos pontuais e marcantes na dinâmica da rede em um determinado ano, através do uso dos indicadores nas redes em modo ano-a-ano, além de identificarmos tendências, estabilidades e mudanças ao longo do tempo nas redes em modo acumulado, quando foi necessário, como no caso do coeficiente de agrupamento e de potência.

Já em relação a própria rede em análise, entendemos que a Comunicação, a partir do conjunto de dados que analisamos, de modo geral, apresenta uma rede altamente fragmentada, evidenciando características de isolamento e baixa articulação entre os seus componentes, não apresentando tendências significativas de mudança desse cenário nos dados analisados. 


\section{REFERÊNCIAS}

BARABASI, A. Linked. Plume. 2003. 256p.

BRITTO, J., Redes empresariais: elementos estruturais e conformação interna. In.

Duarte, F., Quandt, C., Souza, Q. (orgs). 0 tempo das redes. Perspectiva. 2008. 259p.

NEWMAN, M., BARABASI, A., WATTS, D. The structure and dynamics of networks. Princeton University Press. 2006. 624p.

NOOY, W., MRAVAR, A., BATAGELJ, V. Exploratory Social Networks Analysis with Pajek. Structural Analysis in the Social Sciences Series. Cambridge University Press. 2005. 362p.

MARTINS, D. L. Análise de redes sociais de colaboração científica no ambiente de uma federação de bibliotecas digitais. Tese (Doutorado) - Escola de Comunicação e Artes/USP. São Paulo: [s.n.], 2012. 256p.

MARTINS, D. L. ; FERREIRA, S. M. Análise da dinâmica de evolução das revistas científicas e bibliotecas digitais de teses e dissertações em acesso livre na área da Ciências da Comunicação: o caso do repositório Univerciencia.org. Encontros Bibli, v. 17, 2012. p. 136-158.

RAIDER, H., KRACKHARDT, D. J. Intraorganizational Networks. In. Joel, A. C. B. (ed) Companion to organizations. 2001. Pp. 58-74. Oxford, UK:Blackwell.

WASSERMAN, S., FAUST, K. Social network analysis: methods and applications. Cambridge University Press. 1994. 857p.

WATTS, D. Six degrees: the science of a connected age. Norton. 2003. 368p.

WATTS, D. The new science of networks. Annu. Rev. Sociol. 30:43-70. 
